\title{
EFFECT OF PUERPERAL METRITIS ON HOLSTEIN COWS PRODUCTIVE, REPRODUCTIVE VARIABLES AND CULLING RATES
}

\author{
${ }^{1}$ Dawod, A. and ${ }^{2}$ Byeng R. Min \\ ${ }^{1}$ Department of Husbandry and Animal Wealth Development, \\ Faculty of Veterinary Medicine, Sadat City University, Egypt \\ ${ }^{2}$ Department of Agricultural and Environmental Sciences, Tuskegee University, Tuskegee, Al, USA
}

Received 2014-05-01; Revised 2014-06-17; Accepted 2014-09-20

\begin{abstract}
The objective of the study was to determine the effect of puerperal metritis prevalence in high yielding Holstein cows on productive (305 days, actual milk yields), reproductive (days to first estrus, days open and services per conception) variables and culling rates. Throughout the study, 2885 dairy records were collected from high yielding private Holstein dairy farm (average milk yield was up to $9000 \mathrm{~kg}$ ) for 3 successive lactation seasons. Dairy cows were classified according to their uterine affection into two groups, healthy and those with puerperal metritis. Dairy cows which affected with puerperal metritis were diagnosed during the first 3 weeks of lactation. Metritic cows were diagnosed and treated at the discretion of the herd veterinarian. Affected dairy cows were grouped into four groups according to time of the puerperal metritis attack during the first 21 Days In Milk (DIM) as $(<5 ; 5-10 ; 10-15$ and $>15$ DIM, respectively). Moreover, the dairy females were grouped into 3 groups according to frequency of puerperal metritis of once, twice and triple, respectively. Dairy cows were also grouped according to their calving season (winter, spring, summer and fall calving seasons). Productive, reproductive variables and culling due to puerperal metritis were detected from the on-farm record system (DairyComp305). Results of this study revealed that, puerperal metritis had bad effects on high yielding cows productive and reproductive variables, that decreased the 305 milk yield, increased days to first estrus, days open and number of services per conception. Moreover, the occurrence of puerperal metritis increased during the warm months of spring and summer seasons. Also, the occurrence of such disease was increased during the first 10 days of postpartum as $(89.98 \%)$ of the affected cases occurred within this period. Care must be directed to dairy cows which had a history of puerperal metritis as these cases had a greater tendency for recurrence. Also, the re- attacked cows with puerperal metritis had a great chance to be culled from the dairy herds, as they reached to $(53.33 \%$ and $100 \%)$ for the second and third attack, respectively.
\end{abstract}

Keywords: Puerperal Metritis, Dairy Cows, High Yielding Holstein, Culling Rate, Milk Yield, Reproduction

\section{INTRODUCTION}

The lactating dairy cow is not as fertile as she was before. Healthy transitions phase together with smooth calving are critical for the dairy cows lactation performance. Hence that many health hazards may face dairy cows during their transition phase, thus mainly due to suppressed immune system and negative energy balance. Dairy cattle postpartum immune suppression increased the susceptibility of the dairy animal to both metabolic and infectious diseases (Dawod, 2011).

Corresponding Author: Dawod, A., Department of Husbandry and Animal Wealth Development, Faculty of Veterinary Medicine, Sadat City University, Egypt 
One of the most common critical hazards facing early fresh cow during their early lactation phase is the puerperal metritis. Most often metritis was diagnosed within dairy cow's puerperal phase, as it concerns with many dairy cattle problems such as reduced milk production and reproductive fitness during and after the course of the disease (Wittrock et al., 2011).

Puerperal metritis is defined as a diseased case characterized by abnormally enlarged uterus with watery red-brown uterine discharge associated with signs of systemic illness like decreased milk yield, dullness or other signs of toxemia and fever $>39.5^{\circ} \mathrm{C}$, within the first 21 days after parturition. Some other metritic cases exhibited abnormally enlarged uterus with a purulent uterine discharge detectable in the vagina with no systemic signs during the first 3 weeks after calving (Sheldon et al., 2006). Lactating dairy cows suffered from a high incidence of metritis reached to $20 \%$ with wide incidence range $(8->40 \%)$ in some dairy herds (Goshen and Shpigel, 2006; Hammon et al., 2006; Huzzey et al., 2007; Galvão et al., 2009b).

Unfortunately, dairy cows were subjected to metritis during their puerperal phase with a higher incidence rate which reached to $10 \%$ and may exceed in some dairy herds to go up to $20 \%$ (Kelton et al., 1998). Numerous research studies proofed that puerperal metritis had a very huge negative impacts upon dairy herd performance, which caused severe economic losses (LeBlanc et al., 2002; Gilbert et al., 2005). Some expert opinions suggest that, given effective treatments to such disease cases were not of a great efficacious and effort should be focused on dairy herd management strategies to govern puerperal metritis predisposing and risk factors (Galvão, 2013). In concurrent work, effect of puerperal metritis occurrence in high yielding dairy Holstein cows will be studied on productive and reproductive performance. Moreover, its time of attack, attack frequency and culling percentage will be studied for 3 successive lactation seasons.

\section{MATERIALS AND METHODS}

The study was done within a private dairy farm of high yielding Holstein cows located in Giza governorate, Egypt within the period from December, 2013 to February, 2014. The dairy enterprise was considered as one of the high yielding dairy farms as its average milk yield reached up to $9000 \mathrm{~kg}$ milk per season. Throughout the study, about 2885 farm records were collected for 3 successive lactation seasons. The occurrence of puerperal metritis in dairy cows was investigated for several times during the 3 successive lactation seasons using their veterinary health records.

The diagnosis of metritic females was done via herd veterinarian, that the dairy cows which suffered from abnormal enlarged uterus, red-brown watery uterine exudates, high febrile condition $\left(>39.5^{\circ} \mathrm{C}\right)$, general toxemia, loss of appetite and decrease of milk yield during the first 21 days postpartum were diagnosed to be metritic cows (Sheldon et al., 2006). Treatments of such affected cases were done according to standards of herd metritis treatment strategy. Dairy cows were grouped into two main groups according to their uterine affection, as the first affected with puerperal metritis, while the second was healthy (Overton and Fetrow, 2008), other diary cattle diseased cases were discarded from the data. Dairy cows were grouped according to time of the puerperal metritis attack during the first 21 Days In Milk (DIM) into 4 groups, $(<5 ; 5-10 ; 10-15$ and >15 DIM, respectively). Cows were also grouped into three groups according to the frequency of puerperal metritis occurrence, as of once, twice and triple, respectively. Dairy cows were grouped according to their calving season into 4 groups for winter, spring, summer and fall calving seasons, respectively (Dolezel et al. 2008).

\subsection{Statistical Analysis}

Data of 305 days, actual milk yields, days to first estrus, days open, number of services per conception, metritic diseased cases and their culling were collected and obtained from the on-farm record system (DairyComp 305). All data were subjected to further statistical analysis with SPSS analytical software (SPSS, 2006). The effect of the calving season on the puerperal metritis attack, repeated attack on cull and return ratios were done via chi square test according to (Campbell, 2007). The effect of the puerperal metritis upon milk production (305 and actual milk yield) and reproduction (days to first estrus, days open and service per conception) were done using independent t-test according to (McDonald, 2009).

\section{RESULTS}

\subsection{Effect of Puerperal Metritis Prevalence on Dairy Holstein Cows Productive Performance}

Concerning to the effect of puerperal metritis prevalence on dairy Holstein cows milk yield Table 1, it was clearly that the puerperal uterine status influenced 305 days as well as actual milk yield values significantly. As, the dairy cows which suffered from metritis during their puerperal phase decreased significantly 305 days 
milk yield $(9461.58 \pm 292.45 \mathrm{~kg})$ than normal ones $(10087.17 \pm 74.66 \mathrm{~kg})$ at $(\mathrm{p}<0.01)$. The same trend appeared clearly within actual milk yield results, that metritic females decreased significantly the actual milk yield value $(11833.04 \pm 452.57 \mathrm{~kg})$ than normal cows $(12015.67 \pm 174.66 \mathrm{~kg})$ at $(\mathrm{p}<0.01)$.

\subsection{Effect of Puerperal Metritis Prevalence on Dairy Holstein Cows Reproductive Performance}

From Table 2, it was clearly that the reproductive performance possessed significant difference among different uterine statuses in dairy Holstein cows, as the puerperal metritic Holsteins increased significantly days to first estrus, days open and number of services per conception values $(77.60 \pm 4.09$ days; $158.49 \pm 4.85$ days and $2.77 \pm 0.10$, respectively) than normal ones $(48.00 \pm 4.19$ days; $91.17 \pm 7.78$ days and $1.88 \pm 0.27$, respectively).

\subsection{Effect of Days in Milk (DIM) on Puerperal Metritis Prevalence among Dairy Holstein Cows}

Regarding to effect of Days In Milk (DIM) upon puerperal metritis prevalence in dairy Holstein cows Table 3, it was evident that the dairy cattle DIM influenced significantly puerperal metritis among dairy herd. This trend expressed via chi square test (chi square value $\left.\chi^{2}=89.98 * * * *\right)$ at $(\mathrm{p}<0.0001)$, as from 2885,2816 , 2733 and 2713 dairy animals 69 (2.39\%), 83 (2.95\%), 20 $(0.73 \%)$ and $6(0.22 \%)$ for the DIM groups 1 st, $2 \mathrm{nd}, 3 \mathrm{rd}$ and 4 th, respectively suffered from puerperal metritis. From these results it was clearly, that the highest puerperal metritis problem was attained at the 2nd DIM group followed by the 1 st one ( $<5$ days postpartum). The lowest puerperal metritis affection recorded within the 3rd and 4 th DIM groups $(0.69 \%$ and $0.21 \%$, respectively).

From the same table results the proportion of attack females to their total was determined, as the dairy Holstein cows in the 2nd DIM group (5-10 days postpartum) possessed the highest percentage of puerperal metritis prevalence $46.4 \%$, followed with those of the $1^{\text {st }}$ DIM group ( $<5$ days postpartum) which had the percentage of $38.5 \%$ among metritis attacked cases. On the other hand, the lowest prevalence was attained in the 3rd (10-15 days postpartum) and 4th $(<15$ days postpartum) DIM groups $(11.2 \%$ and $3.4 \%$, respectively). The overall percentage of puerperal prevalence of the first two DIM groups recorded $84.9 \%$ of puerperal metritic cases. Both the $1^{\text {st }}$ and $2^{\text {nd }}$ DIM groups sustained $5.27 \%$ from the total herd percentage, as $84.9 \%$ of the puerperal metritic females were located within. From foregoing results it was clearly that $5.72 \%$ of the dairy cows affected with puerperal metritis during the first 10 days in early postpartum, that about $84.9 \%$ of the affected cows attacked with metritis during this period.

\subsection{Effect of Calving Season on Puerperal Metritis Prevalence among Dairy Holstein Cows}

Dairy cattle calving season reflects greatly on the prevalence of puerperal metritis Table 4. These phenomena expressed via chi squire test (chi squire value $\chi^{2}=$ $\left.19.41^{* * * *}\right)$ at $(\mathrm{p}<0.0001)$. Spring calving cows had the highest puerperal metritis prevalence $22(10.33 \%)$ followed with those which calved during summer season 65 (8.42\%). While, the lower puerperal metritis prevalence obtained in winter 35 (4.65\%) and fall 56(4.88\%) calving cows.

\subsection{Frequency of Puerperal Metritis Prevalence and Culling Rates among Dairy Holstein Cows}

The recurrence of puerperal metritis prevalence was determined among dairy females for 3 successive lactation seasons Table 5. The puerperal metritis attack tended to be recurrent in some dairy females. This trend expressed via chi square test (Chi square $\chi^{2}=$ $243.27 * * * *)$ at $(\mathrm{p}<0.0001)$. As, Dairy females were affected with puerperal metritis for once, twice and triple times with the prevalence of $5.55 \% ; 0.53 \%$ and $0.11 \%$, respectively. Same trend appeared when these metritic females compared with their total that $89.89 \%$ of these females affected with metritis during their puerperium for once. Dairy cows could be re-attacked with metritis in their next puerperal phase by $8.43 \%$. Also, the chance of puerperal metritis third attack would remain in dairy cows which had a history of metritis by $1.69 \%$.

Regarding to the dairy cows culling due to metritis attack Table 6 it was clearly, that the frequency of puerperal metritis attack possesses a significant effect on the puerperal metritis culling percentage in high yielding dairy Holsteins. This expressed via chi square test (chi squire value $\chi 2=9.52 * * *)$ at $(\mathrm{p}<0.001)$. Same table expressed that the percentage of culling was increased with the increase of puerperal metritis frequency of attack. This trend appeared clearly, that out of $160 ; 15$ and 3 puerperal metritic females 48 (30\%); 8 (53.33\%) and $3(100 \%)$ females were culled for once, twice, triple attack, respectively. The highest culling percentage was recorded within the 3rd group (triple frequency of puerperal metritis attack), while the lowest attained within the 1st group (puerperal metritis attack for once). 
Table 1. Effect of uterine status of the examined Holstein dairy cows on their milk

\begin{tabular}{lll}
\hline Uterine status & 305 milk yield & Actual milk yield \\
\hline & Mean \pm SE & Mean \pm SE \\
Puerperal metritis & $9461.58 \pm 292.45$ & $11833.04 \pm 452.57$ \\
Normal & $10087.17 \pm 74.66^{* *}$ & $12015.67 \pm 174.66^{* *}$ \\
\hline
\end{tabular}

* means of uterine status groups differed significantly at $(\mathrm{p}<0.05)$

** means of uterine status groups different significantly at $(\mathrm{P}<0.01)$

Table 2. Effect of puerperal metritis occurrence on the reproductive performance of Holstein dairy cows

\begin{tabular}{llll}
\hline Uterine status & Days to first estrus & Days open & Service per conception \\
\hline & Mean \pm SE & Mean \pm SE & Mean \pm SE \\
Puerperal metritis & $77.60 \pm 4.09^{*}$ & $158.49 \pm 4.85^{* *}$ & $2.77 \pm 0.10^{*}$ \\
Normal & $48.00 \pm 4.19$ & $91.17 \pm 7.78$ & $1.88 \pm 0.27$ \\
\hline
\end{tabular}

* means of uterine status groups differed significantly at $(\mathrm{p}<0.05)$

** means of uterine status groups different significantly at $(\mathrm{P}<0.01)$

Table 3. Effect of DIM on puerperal metritis occurrence among dairy Holstein cows

\begin{tabular}{|c|c|c|c|c|c|}
\hline \multirow[b]{2}{*}{ Group } & \multirow[b]{2}{*}{ DIM (days) } & \multirow[b]{2}{*}{ Total number } & \multicolumn{2}{|c|}{ Puerperal metritis } & \multirow{2}{*}{$\begin{array}{l}\text { Proportion to puerperal } \\
\text { metritis cases }(\%)\end{array}$} \\
\hline & & & Number & $\%$ & \\
\hline 1 & $<5$ & 2885 & 69 & 2.39 & 38.5 \\
\hline 2 & $5-10$ & 2816 & 83 & 2.95 & 46.4 \\
\hline 3 & $10-15$ & 2733 & 20 & 0.73 & 11.2 \\
\hline 4 & $>15$ & 2727 & 6 & 0.22 & 3.4 \\
\hline
\end{tabular}

Chi square $\chi^{2}=89.98 * * * * \mathrm{p}<0.0001$

Table 4. Effect of calving season on puerperal metritis occurrence among Holstein dairy cows

\begin{tabular}{lllr} 
& & Puerperal metritis & $\%$ \\
Calving season & Total number & Number & 4.65 \\
\hline Winter & 752 & 35 & 10.33 \\
Spring & 213 & 22 & 8.42 \\
Summer & 772 & 65 & 4.88 \\
Fall & 1148 & 56 & \\
\hline
\end{tabular}

Chi square $\chi^{2}=19.41 * * * * \mathrm{p}<0.0001$

Table 5. Frequency of puerperal metritis prevalence among dairy Holstein cows

\begin{tabular}{llllll}
\hline & & & Puerperal metritis cows & Proportion to puerperal \\
Group & Puerperal & Number of & - Number & $\%$ & 89.89 \\
\hline 1 & metritis prevalence & total herd & 160 & 5.55 & 8.43 \\
2 & Once & 2885 & 15 & 0.53 & 1.69 \\
3 & Twice & 2837 & 3 & 0.11 & \\
\hline
\end{tabular}

Chi square $\chi^{2}=243.27 * * * * \mathrm{p}<0.0001$

Table 6. Effect of frequency of puerperal metritis occurrence on the culling percentage in Holstein dairy cows

\begin{tabular}{llccc} 
& & & Puerperal metritis culled cows \\
Group & Puerperal & Total affected & Number & $\%$ \\
\hline 1 & metritis prevalence & cases & 160 & 48 \\
2 & Once & 15 & 8 & 30.00 \\
3 & Twice & 3 & 3 & 53.33 \\
\hline
\end{tabular}

Chi square $\chi^{2}=9.52 * * * \mathrm{p}<0.001$ 
Dawod, A. and Byeng R. Min / American Journal of Animal and Veterinary Sciences 9 (3): 162-169, 2014

Table 7. Fate of dairy Holstein cows affected with puerperal metritis

\begin{tabular}{|c|c|c|c|c|c|c|c|}
\hline \multirow[b]{2}{*}{ Group } & \multirow[b]{2}{*}{$\begin{array}{l}\text { Puerperal } \\
\text { metritis prevalence }\end{array}$} & \multirow{2}{*}{$\begin{array}{l}\text { Number of } \\
\text { puerperal metritis }\end{array}$} & \multirow{2}{*}{$\begin{array}{l}\text { Number of } \\
\text { total her }\end{array}$} & \multicolumn{2}{|c|}{ Returned to herd } & \multicolumn{2}{|c|}{ Culled from herd } \\
\hline & & & & Number & $\%$ & Number & $\%$ \\
\hline 1 & Once & 160 & 2885 & 112.00 & 3.88 & 48.00 & 1.66 \\
\hline 2 & Twice & 15 & 2837 & 7.00 & 0.25 & 8.00 & 0.28 \\
\hline 3 & Triple & 3 & 2829 & 0.00 & 0.00 & 3.00 & 0.11 \\
\hline Total & 178 & 2885 & 119 & 4.13 & 59.00 & 2.05 & \\
\hline
\end{tabular}

\subsection{Fate of Dairy Holstein Cows Affected With Puerperal Metritis}

An interesting finding of our study is that the fate of the dairy cows is associated with the puerperal metritis prevelance for once or several times Table 7. The results referred to the total puerperal metritis within the high yielding dairy Holstein herd reached to $6.17 \%$ within the period of three successive lactation seasons. Moreover, about $4.13 \%$ of the affected cases return to the dairy herd, while the rest were culled $2.05 \%$. Culling and remaining of the dairy cows from the dairy herds were depending on the disease history of puerperal metritis attack, as the culling percentages were $1.66 \% ; 0.28 \%$ and $0.11 \%$ for once, twice and triple puerperal metritis attack, respectively. While, the remaining within the dairy herd percentages were $3.88 \% ; 0.25$ and $0 \%$ for once, twice and triple attack of puerperal metritis, respectively.

\section{DISCUSSION}

\subsection{Effect of Puerperal Metritis Prevalence on Dairy Holstein Cows Productive Performance}

Lactating dairy cows are susceptible to numerous infectious and metabolic diseases during the early postpartum period. Puerperal metritis, or early metritis, is a postpartum disease known to reduce milk yield (Rajala and Grohn, 1998) and feed intake (Huzzey et al., 2007) and to negatively affect reproductive performance (Melendez et al., 2004).

Similarly to the results obtained by others (Fourichon et al., 1999; Deluyker et al., 1991; Rajala and Grohn, 1998; Huzzey et al., 2007; Proudfoot et al., 2009), the present study showed a decrease in the milk production (305 and actual yields) in the puerperal affected dairy cows than healthy ones. The results could be attributed to decrease of the feed intake during the course of the disease in addition to the inflammatory toxins which caused illness signs (depression, weakness, fever $>39.5^{\circ} \mathrm{C}$ and loss of appetite). Huzzey et al., 2007;
Proudfoot et al., 2009 reported that, cows with metritis had a low feed intake. The reduction in feed intake in the first 21 days in lactation explained the lower daily milk yield observed in such cases over the first 20 weeks of lactation.

Fourichon et al. (1999; Deluyker et al., 1991) reported that metritic dairy cows within the first 21 lactation day's loss about 4.9 pounds per day from their average milk yield during the first 120 days postpartum compared to normal herdmate. While, Rajala and Grohn (1998) proofed that, dairy cows which had a puerperal metritis loss 6 pounds of their milk yield each day, but only for a period of about 2 weeks for the disease course. In contrast, other researches indicate that affection of the dairy cows during early lactation had an overall negative impact on the milk production in multiparous cows, as these animals produced less milk than those which remained healthy. This milk yield reduction was experienced not only during the metritis attack but also throughout the first 20 weeks of lactation, even though all sick cows received veterinary treatments (Huzzey et al., 2007; Proudfoot et al., 2009).

From the outgoing results it was evident that puerperal metritis considered as a huge economic loss, as it could be produced about $2371.46 \mathrm{~kg}$ milk yield loss per each dairy Holstein cow on 305 days milk yield bases. While, on the actual dairy milk bases this milk loss tended to somewhat decreased to $1928.5 \mathrm{~kg}$ per each dairy cow. The results could be attributed to metritic cows had much longer days open period than normal ones, thus increased their actual lactation length than normal cows. So, the average of actual milk yield loss in such affected cows somewhat lowered than the average of 305 milk yield loss.

\subsection{Effect of Puerperal Metritis Prevalence on Dairy Holstein Cows Reproductive Performance}

Good reproductive efficiency is an important factor for production economy in a dairy herd. Metritis is one of the most common cattle diseases that can be a significant cause of poor reproduction (Overton et al., 2003; Wittrock et al., 2011), even though some investigations 
show a rather limited effect (Markusfeld and Ezra, 1993). Current study also clearly show that the reproductive performance possessed significant difference among different uterine statuses in dairy Holstein cows.

The present study evident that the puerperal metritis affected the dairy cows reproduction so badly. These results agreed with (Overton and Fetrow, 2008; Galvão et al., 2009a; 2009b). Metritis causes a depression in dairy cattle fertility, as it increased the days open value by 18 days and a declined the 21-day pregnancy rate by 3-6\% (Overton and Fetrow, 2008). Most of the negative effects of puerperal metritis were due to extend of dairy cows days open, as it increased the days open by about 13-28 days (Fourichon et al., 2000). Uterine diseases (puerperal metritis, clinical metritis, clinical endometritis and subclinical endometritis) have been associated with increased service preconception, extended days open, increased culling and economic losses (Gilbert et al., 2005; Overton and Fetrow, 2008; Galvão et al., 2009a; 2009b).

Metritic dairy cows had very high days open value than normal ones, which were differed from each other with high significant value at $(\mathrm{P}<0.01)$. These phenomena could be much more costly for the high yielding dairy farming. The dairy investments spent much more money in treatment of such diseased cases in addition to the dairy cows loss many chances to be pregnant. This problem may lead to extra service costs, which appeared clearly in the number of services per conception results. As, the metritic dairy Holstein consumed about (2.77) semen straw to be pregnant, thus could be costly for the dairy Holstein farms. Dairy producers spent a lot of money in parching of high genetic merit semen straws with its higher prices. In contrast, normal dairy cows in high yielding Holstein dairy farms remained the number of semen straws used for insemination per each dairy cow much lower (1.88) than metritic ones. However, this figure may be increased somewhat than the normal value of dairy Holsteins (1.7). Thus, may be due to the stress of high milk yield in such cows. The high milk yield affected the dairy cow's reproduction so badly (Leroy and De-Kruif, 2006). These results were in agreement with those of (Fourichon et al., 2000; Gilbert et al., 2005; Overton and Fetrow, 2008; Galvão et al., 2009a; 2009b), as they reported that metritis had a great negative impacts on reproduction, as it decreased pregnancy rate, extended open period, increased culling rate and economic losses.

Fourichon et al. (2000) stated that, the main effect of the puerperal metritis on the dairy cattle reproduction was days open, as it could be increase by 13-28 days above its normal value in puerperal metritic females. The negative effects of the puerperal metritis upon fertility were due to the negative effects on the uterine wall and ovary. As, the dairy cattle puerperal metritis caused lesions on the endometrium (Bonnett et al., 1991), these lesions disrupt endometrial function (Sheldon and Dobson, 2004) and impair embryo development (Hill and Gilbert, 2008).

\subsection{Effect of Days in Milk (DIM) on Puerperal Metritis Prevalence among Dairy Holstein Cows}

Across days in milk the highest puerperal metritis prevelance recorded during the first 10 days postpartum. These results were somewhat lower than those of (Huzzey et al., 2007; Galvão et al., 2009b), as they reported that the incidence of metritis in the dairy herds was $20 \%$ with the range of 8 to $>40 \%$ in some dairy herds. Thus, may be attributed to the prevalence of metritis in this study was estimated during shorter postpartum period (21 days postpartum).

\subsection{Effect of Calving Season on Puerperal Metritis Prevalence among Dairy Holstein Cows}

The prevalence of puerperal metritis increased significantly during the spring and summer calving seasons. These results could be due to the magnitude of the postpartum immune suppression during warm months which may result from excessive heat stress, as most of these periods had a high temperature degree under Egyptian atmospheric conditions. The results agreed with (Dolezel et al., 2008) and disagreed with (Benzaquen et al., 2007), as they reported that the incidence of the puerperal metritis in primiparous cows increased in warm seasons than cool seasons, while these phenomena were disappeared in multiparous cows. In contrast, Dolezel et al. (2008) found that the incidence of the puerperal metritis was increased during the spring calving season.

\subsection{Frequency of Puerperal Metritis Prevalence and Culling Rates among Dairy Holstein Cows}

The puerperal metritis attack in high yeilding Holsteins may have the tendancy to be recurant. The culling percentage increased with the increase of frequency of dairy cattle attack. These results could be due to the cumulative effect of the puerperal metritis attack on dairy cattle production and reproductive parameters, as by the time the re-attack with metritis promoted its bad effects on dairy performance. Dolezel et al. (2008) recorded that the puerperal metritis depressed high yielding dairy cows first serving pregnancy, increased 
days open, service preconception and calving intervals. This explained the high culling rates of dairy cows attacked with metritis for second and third times.

The results referred to dairy cows which attacked with puerperal metritis for twice had high culling percent as the culling percentage of such cows reached over the half of their percentage $(53.33 \%)$. While, the triple metritis attack prevents dairy cows from standing within dairy herd, as the culling percentage in such condition be $100 \%$. These results go in parallel with those of (Huzzey et al., 2007; Proudfoot et al., 2009), who reported that about $50 \%$ of multiparous cows whom suffered from metritis were culled from the dairy herds within the first 60 days in lactation.

\subsection{Fate of Dairy Holstein Cows Affected With Puerperal Metritis}

This study reported that the probability of the dairy cows to return to their dairy herd after puerperal metritis attack is somewhat limited, while the culling probability is much higher. These results were in agreement with those of (Huzzey et al., 2007; Proudfoot et al., 2009), who reported that the half of metritic multiparous cows were culled from their herds within early 60 days of lactation.

The results disagreed with (Overton and Fetrow, 2008), who reported that dairy cows affected with metritis have an increased culling risk of $5.3 \%$ during the first 60 days in milk. Also, the culling risk could be reached to $14 \%$ after the first 60 days in milk and the breeding peroid.

\section{CONCLUSION}

Puerperal metritis had great negative impacts upon high yielding Holstein cows productive and reproductive performance even after efficient treatment, as it could be decreased the milk yield by about $2371.46 \mathrm{~kg}$ per season on 305 milk yield bases. Also, it increased days to first estrus, days open and number of services per conception. Moreover, concern must be given to the dairy females, which calving during spring and summer seasons, as these seasons have high prevalence of puerperal metritis.

Dairy producers must be focusing their efforts to detect puerperal metritis within the first ten days of the postpartum period. Since most of such cases appeared during this period by a rate of $89.98 \%$. Attention should be taken to reappearance of the puerperal metritis during successive lactation seasons in the dairy females whom had a history of puerperal metritis as this disease had tended to be recurrent. Moreover, the re-attack of puerperal metritis during the second and third successive lactation season, preventing the dairy cows from withstanding in dairy herds, as the culling percentage was 53.33 and $100 \%$, respectively for such diseased females. Further researches in the near future must be directed to prevention of puerperal metritis, as most of effective treatments don't prevent the negative impacts of such disease upon dairy, reproduction and culling percentage within dairy herd.

\section{REFERENCES}

Benzaquen, M.E., C.A. Risco, L.F. Archbald, P. Melendez and M.J. Thatcher, 2007. Rectal temperature, calvingrelated factors and the incidence of puerperal metritis in postpartum dairy cows. J. Dairy Sci., 90: 2804-2814. DOI: $10.3168 /$ jds.2006-482

Bonnett, B.N., S.W. Martin, V.P.J. Gannon, R.B. Miller and W.G. Etherington, 1991. Endometrial biopsy in Holstein-Friesian dairy cows. III. Bacteriological analysis and correlations with histological findings.. Can. J. Vet. Res., 55: 168-173. PMID: 1884297

Campbell, I., 2007. Chi-squared and Fisher-Irwin tests of two-by-two tables with small sample recommendations. Statist. Med., 26: 3661-3675. PMID: 17315184

Dawod, A., 2011. Effect of management practices during transition period on performance of dairy cattle. PhD. Thesis, Menofia University, Egypt.

Deluyker, H.A., J.M. Gay, L.D. Weaver and A.S. Azari, 1991. Change of milk yield with clinical diseases for high producing dairy herd. J. Dairy Sci., 74: 436445. DOI: 10.3168/jds.S0022-0302(91)78189-7

Dolezel, R., M. Vecera, T. Palenik, S. Cech and M. Vyskocil, 2008. Systematic clinical examination of early postpartum cows and treatment of puerperal metritis did not have any beneficial effect on subsequent reproductive performance. Vet. Med., 53: 59-69.

Fourichon, C., H. Seegers, N. Bareille and F. Beaudeau, 1999. Effect of disease on milk production in dairy cow: A review. Prev. Vet. Med., 41: 1-35. DOI: 10.1016/S0167-5877(99)00035-5

Fourichon, C., H. Seegers and X. Malher, 2000. Effect of disease on reproduction in the dairy cow: A meta analysis. Theriogenology, 53: 1729-1759. DOI: 10.1016/S0093-691X(00)00311-3

Galvão, K.N., M. Frajblat, S.B. Brittin, W.R. Butler and C.L. Guard et al., 2009a. Effect of prostaglandin F2alpha on subclinical endometritis and fertility in dairy cows. J. Dairy Sci., 92: 4906-4913. DOI: 10.3168/jds.2008-1984 
Galvão, K.N., L.F. Greco, J.M. Vilela, M.F. Sá Filho and J.E.P. Santos, 2009b. Effect of intrauterine infusion of ceftiofur on uterine health and fertility in dairy cows. J. Dairy Sci., 92: 1532-1542. DOI: $10.3168 /$ jds.2008-1615

Galvão, K.N., 2013. Uterine diseases in dairy cows: understanding the causes and seeking solutions. Anim. Reprod., 10: 228-238.

Gilbert, R.O., S.T. Shin, C.L. Guard, H.N. Erb and M. Frajblat, 2005. Prevalence of endometritis and its effects on reproductive performance of dairy cows. Theriogenology, 64: 1879-1888. DOI: 10.1016/j.theriogenology.2005.04.022

Goshen, T. and N.Y. Shpigel, 2006. Evaluation of intrauterine antibiotic treatment of clinical metritis and retained fetal membranes in dairy cows. Theriogenology, 66: 2210-2218. DOI: 10.1016/j.theriogenology.2006.07.017

Hammon, D.S., I.M. Evjen, T.R. Dhiman, J.P. Goff and J.L. Walters, 2006. Neutrophil function and energy status in Holstein cows with uterine health disorders. Vet. Immunol. Immunopathol., 113: 21-29. DOI: 0.1016/j.vetimm.2006.03.022

Hill, J. and R. Gilbert, 2008. Reduced quality of bovine embryos cultured in media conditioned by exposure to an inflamed endometrium. Aust. Vet. J., 86: 312316. DOI: 10.1111/j.1751-0813.2008.00326.x

Huzzey, J.M., D.M. Veira, D.M. Weary and M.A. von Keyserlingk, 2007. Prepartum behavior and dry matter intake identify dairy cows at risk for metritis. J. Dairy Sci., 90: 3220-3233. DOI: 10.3168/jds.2006-807

Kelton, D.F., K.D. Lissemore and R.E. Martin, 1998. Recommendations for recording and calculating the incidence of selected clinical diseases of dairy cattle. J. Dairy Sci., 81: 2502-2509. DOI: 10.3168/jds.S0022-0302(98)70142-0

LeBlanc, S.J., T.F. Duffield, K.E. Leslie, K.G. Bateman and G.P. Keefe et al., 2002. Defining and diagnosing postpartum clinical endometritis and its impact on reproductive performance in dairy cows. J. Dairy Sci., 85: 2223-2236. DOI: 10.3168/jds.S0022-0302(02)74303-8

Leroy, J.L.M.R. and A. De Kruif, 2006. Reduced reproductive performance in high producing dairy cows: Is there actually a problem? Vlaams Diergeneeskundig Tijdschrift, 75: 55-60.

Markusfeld, O. and E. Ezra, 1993. Body measurements, metritis and postpartum performance of first lactation cows. J. Dairy Sci., 76: 3771-3777. PMID: 8132884
McDonald, J.H., 2009. Handbook of Biological Statistics. 1st Edn., Sparky House Publishing, Baltimore, pp: 313.

Melendez, P., J. McHale, J. Bartolome, L.F. Archbald and G.A. Do-novan, 2004. Uterine involution and fertility of holstein cows subsequent to early postpartum PGF2alpha treatment for acute puerperal metritis.. J. Dairy Sci., 87: 3238-3246. PMID: 15377603

Overton, M.W., W.M. Sischo and J.P. Reynold, 2003. Evaluation of effect of estradiol cypionate administered prophylactically to postparturient dairy cows at high risk for metritis. J. Am. Vet. Med. Assoc., 223: 846-851. PMID: 14507103

Overton, M. and J. Fetrow, 2008. Economics of postpartum uterine health. Proceedings of the Dairy Cattle Reproduction Council Convention, (DCR '08), Omaha, NE, USA. Hartland, WI: DCRC., pp: 39-43.

Proudfoot, K.L., D.M. Veira, D.M. Weary and M.A.G. von Keyserlingk, 2009. Competition at the feed bunk changes the feeding, standing and social behavior of transition dairy cows. J. Dairy Sci., 92: 3116-3123. DOI: $10.3168 /$ jds.2008-1718

Rajala, P. J. and Y.T. Grohn, 1998. Effects of dystocia, retained placenta and metritis on milk yield in dairy cows. J. Dairy Sci., 81: 3172-3181. DOI: 10.3168/jds.S0022-0302(98)75883-7

Sheldon, I.M. and H. Dobson, 2004. Postpartum uterine health in cattle. Anim. Reprod. Sci., 82/83: 295-306. DOI: 10.1016/j.anireprosci.2004.04.006

Sheldon, I.M., G.S. Lewis, S. LeBlanc and R.O. Gilbert, 2006. Defining postpartum uterine disease in cattle. Theriogenology, 65: 1516-1530. DOI: 10.1016/j.theriogenology.2005.08.021

SPSS, 2006. SPSS 15.0 Brief Guide. 1st Edn., SPSS Inc., Chicago, USA.

Wittrock, J.M., K.L. Proudfoot, D.M. Weary and M.A. von Keyserlingk, 2011. Short communication: Metritis affects milk production and cull rate of Holstein multiparous and primiparous dairy cows differently. J. Dairy Sci., 94: 2408-2412. DOI: 10.3168/jds.2010-3697 